\title{
Effect of Serotonin on Paired Associative Stimulation-Induced Plasticity in the Human Motor Cortex
}

\author{
Giorgi Batsikadze', Walter Paulus', Min-Fang Kuo ${ }^{1,2}$ and Michael A Nitsche*,1,2 \\ 'Clinic of Clinical Neurophysiology, Georg-August-University of Göttingen, Göttingen, Germany
}

\begin{abstract}
Serotonin modulates diverse brain functions. Beyond its clinical antidepressant effects, it improves motor performance, learning and memory formation. These effects might at least be partially caused by the impact of serotonin on neuroplasticity, which is thought to be an important foundation of the respective functions. In principal accordance, selective serotonin reuptake inhibitors enhance long-term potentiation-like plasticity induced by transcranial direct current stimulation (tDCS) in humans. As other neuromodulators have discernable effects on different kinds of plasticity in humans, here we were interested to explore the impact of serotonin on paired associative stimulation (PAS)-induced plasticity, which induces a more focal kind of plasticity, as compared with tDCS, shares some features with spike timing-dependent plasticity, and is thought to be relative closely related to learning processes. In this single-blinded, placebo-controlled, randomized crossover study, we administered a single dose of $20 \mathrm{mg}$ citalopram or placebo medication and applied facilitatory- and excitability-diminishing PAS to the left motor cortex of 14 healthy subjects. Cortico-spinal excitability was explored via single-pulse transcranial magnetic stimulation-elicited MEP amplitudes up to the next evening after plasticity induction. After citalopram administration, inhibitory PAS-induced after-effects were abolished and excitatory PAS-induced after-effects were enhanced trendwise, as compared with the respective placebo conditions. These results show that serotonin modulates PAS-induced neuroplasticity by shifting it into the direction of facilitation, which might help to explain mechanism of positive therapeutic effects of serotonin in learning and medical conditions characterized by enhanced inhibitory or reduced facilitatory plasticity, including depression and stroke. Neuropsychopharmacology (2013) 38, 2260-2267; doi:I0.1038/npp.2013.127; published online 5 June 2013
\end{abstract}

Keywords: neuroplasticity; serotonin; paired associative stimulation; human; motor cortex; depression

\section{INTRODUCTION}

Serotonin (5-HT) is a widely distributed neurotransmitter in the brains of animals and humans, affecting various physiological functions such as learning, memory formation, pain perception, mood and the sleep-wakefulness cycle (Bert et al, 2008; Geyer, 1996; Hasbroucq et al, 1997; Jacobs and Fornal, 1997; Meneses, 1999). One important foundation for these effects might be its impact on neuroplasticity. Activation of serotoninergic subreceptors is shown to affect long-term potentiation (LTP) or longterm depression (LTD) in animal slice preparations, depending on subreceptor type, location and frequency of application (Huang and Kandel, 2007; Kojic et al, 1997; Mori et al, 2001).

In the clinical domain, studies have suggested that depression might be a result of altered brain plasticity (Christoffel et al, 2011; Garcia, 2002; Henn and Vollmayr, 2004; Popoli et al, 2002), on which serotonin has a major

* Correspondence: Professor/Dr MA Nitsche, Clinic of Clinical Neurophysiology, Georg-August-University of Göttingen, Robert Koch Straße 40, 37075 Göttingen, Germany, Tel: +49 55I 39 957I, Fax: +4955। 39 8126, E-mail: mnitschl@gwdg.de

${ }^{2}$ These authors contributed equally to this work.

Received 13 March 2013; revised 29 April 2013; accepted I4 May 2013; accepted article preview online 17 May 2013 impact. Distress has been proposed as one of the main factors preceding depression (Caspi et al, 2003), and in animals it inhibits LTP and facilitates LTD induction (Foy et al, 1987; Rocher et al, 2004; Shors et al, 1989; Xu et al, 1997). In accordance, LTD is facilitated in animal models of depression, which was prevented by chronic application of the selective serotonin reuptake inhibitor (SSRI) fluvoxamine (Holderbach et al, 2007). Besides depression, several studies have demonstrated that SSRIs improve motor functions in stroke patients (Chollet et al, 2011; Dam et al, 1996; Pariente et al, 2001) and in healthy individuals (Loubinoux et al, 1999; Loubinoux et al, 2002a; Loubinoux et al, 2002b; Loubinoux et al, 2005). Again, the physiological basis for this effect might be the impact of serotonin on plasticity.

Recently it was shown that motor cortex plasticity in healthy humans induced by transcranial direct current stimulation (tDCS) was affected by single-dose SSRI. Citalopram enhanced facilitatory plasticity induced by anodal tDCS and converted cathodal tDCS-induced inhibitory plasticity into facilitation (Nitsche et al, 2009). tDCS and paired associative stimulation (PAS) are non-invasive brain stimulation techniques inducing changes in cortical excitability that outlast the stimulation duration (Nitsche et al, 2003b; Nitsche and Paulus, 2000, 2001; Stefan et al, 2000; Wolters et al, 2003). These alterations in cortical 
excitability are NMDA- and $\mathrm{Ca}^{2+}$-dependent (Nitsche et al, 2003a; Stefan et al, 2002; Wolters et al, 2003). tDCS induces non-focal plasticity, affecting relatively non-selectively neuronal populations beneath the large stimulation electrodes via subthreshold resting membrane potential modulation (Nitsche et al, 2008; Nitsche et al, 2007; Purpura and McMurtry, 1965). PAS induces focal and synapse-specific plasticity of the respective target neurons. In PAS, a repetitive electric pulse to a peripheral nerve at an intensity that activates somatosensory afferents is combined with transcranial magnetic stimulation (TMS) over the corresponding area of the primary motor cortex. Depending on the interstimulus interval (ISI), synchronous or asynchronous activation of the target group of neurons, which are motor cortex neurons connected with the respective somatosensory afferents, is accomplished, resulting in excitatory or inhibitory after-effects (Stefan et al, 2000). This mechanism of plasticity induction resembles some characteristics of spike timing-dependent plasticity (STDP), which is closely linked to learning and memory processes.

Interestingly, other neuromodulators have discernable effects of tDCS- and PAS-induced plasticity. Specifically, dopamine, acetylcholine, and nicotine have a focusing, or signal-enhancing effect on facilitatory plasticity (Kuo et al, 2007; Kuo et al, 2008; Monte-Silva et al, 2010; Thirugnanasambandam et al, 2012). These substances abolish tDCS-induced non-focal, but enhance PAS-generated focal facilitatory plasticity. This effect might explain the cognition- and behavior-enhancing impact of these substances.

After having explored the impact of serotonin on tDCSinduced plasticity, we were now interested to explore how this modulator affects PAS-generated neuroplastic cortical excitability alterations. We hypothesize that citalopram enhances PAS-induced focal excitatory plasticity and abolishes focal inhibitory plasticity or convert it into excitation, as it was shown for tDCS (Nitsche et al, 2009).

\section{MATERIALS AND METHODS}

\section{Subjects}

Fourteen healthy subjects aged $28.1 \pm 4.7$ years $(7$ males/7 females) were recruited. All subjects were right-handed according to the Edinburgh handedness inventory (Oldfield, 1971). None of them took any medication, had a history of a neuropsychiatric disease, present pregnancy, or metallic head implants. All volunteers gave written informed consent and were compensated for participation. The investigation was approved by the Ethics Committee of the University of Göttingen, and conforms to the principles laid down in the Declaration of Helsinki.

\section{Paired Associative Stimulation}

The peripheral electric pulse was delivered over the right ulnar nerve at the level of the wrist, followed by a TMS pulse over the M1 representation of the abductor digiti minimi muscle (ADM) at ISIs of 10 (PAS10) or $25 \mathrm{~ms}$ (PAS25). The peripheral pulse was delivered by a Digitimer D184 multipulse stimulator (Digitimer, Welwyn Garden City, UK) at an intensity of $300 \%$ of the sensory perceptual threshold.
The TMS pulse was delivered by a Magstim 200 stimulator with an intensity to elicit single-pulse MEPs with peak-topeak amplitudes of on average $1 \mathrm{mV}$. The participants were instructed to count silently the number of pulses they received at their wrist during the whole stimulation duration to guarantee sufficient attention to the procedure, which has been shown to be crucial to obtain the intended after-effects (Stefan et al, 2000; Stefan et al, 2004).

\section{Pharmacological Interventions}

Citalopram (20 mg) or equivalent placebo (PLC) drugs were administered $2 \mathrm{~h}$ before the start of the experimental session, allowing the verum drug to induce a stable plasma level and produce prominent effects in the central nervous system (Bezchlibnyk-Butler et al, 2000; Kragh-Sorensen et al, 1981; Robol et al, 2004).

\section{Monitoring of Motor Cortical Excitability}

MEPs were recorded from the right ADM by single-pulse TMS over the left primary motor cortex, conducted by a Magstim 200 magnetic stimulator (Magstim, Whiteland, Dyfed, UK) with a figure-of-eight magnetic coil (diameter of one winding $-70 \mathrm{~mm}$; peak magnetic field $-2.2 \mathrm{~T}$ ). The coil was held tangentially to the skull, with the handle pointing backwards and laterally at $45^{\circ}$ from the midline. The optimal coil placement (hotspot) was defined as the site where TMS resulted consistently in the largest MEPs of the contralateral ADM. Surface MEPs were recorded from the right $\mathrm{ADM}$ with $\mathrm{Ag}-\mathrm{AgCl}$ electrodes in a belly-tendon montage. The signals were amplified, and band-pass filtered ( $2 \mathrm{~Hz}$ to $2 \mathrm{kHz}$, sampling rate, $5 \mathrm{kHz}$ ). Signals were digitized with a micro $1401 \mathrm{AD}$ converter (Cambridge Electronic Design, Cambridge, UK), controlled by Signal Software (Cambridge Electronic Design, v. 2.13) and stored for offline analysis.

\section{Experimental Procedures}

Each subject participated in four experimental sessions (PAS25 with citalopram or placebo, PAS10 with citalopram or placebo), which were carried out in randomized order and separated by minimum 1 week. A unique sequence of experimental sessions was randomly generated for each subject individually, which did not match any previously generated one for other subjects. The volunteers were seated in a comfortable chair with head and arm rests. First, the hotspot (the position of coil that produced the largest MEPs of the right ADM) was identified by TMS. Then the stimulation intensity was adjusted to elicit single-pulse MEPs with peak-to-peak amplitudes of on average $1 \mathrm{mV}$ and 25 MEPs were recorded for the first baseline determination. After baseline recording, citalopram or placebo medication was administered. At $2 \mathrm{~h}$ after intake of medication, a second baseline was recorded to monitor for a possible influence of the drug on cortical excitability (baseline 2), and TMS intensity was adjusted, if necessary (baseline 3). After that procedure, PAS25 or PAS10 was administered and 25 MEPs were recorded immediately after stimulation and at time points of 5, 10, 15, 20, 25, 30, 60, 90 and $120 \mathrm{~min}$ after the stimulation PAS. Further TMS measurements were 
conducted in the evening of the same day (SE), next morning, at $\sim 0900$ hours (NM), next noon, at $\sim 1200$ hours (NN), and next evening, at $\sim 1800$ hours (NE) (Figure 1). To keep the EMG electrodes and TMS coil at the same place for later measurements, their positions were marked with a waterproof pen. Subjects were blinded for both, stimulation and medication conditions; the experimenter was blinded only for the medication condition.

\section{Analysis and Statistics}

The experimenter was unblinded after finishing data collection and analysis. The individual means of 25 MEP amplitudes were calculated for all subjects and the afterstimulation mean MEP amplitudes were normalized to the respective mean baseline MEP amplitudes (quotient of postPAS MEPs $v s$ baseline values). Then the grand averages for each time point were calculated. A repeated measures ANOVA was performed on the above-mentioned data using MEP amplitude as the dependent variable and medication, stimulation type and time course as within-subject factors. The Mauchly test of sphericity was performed and the Greenhouse-Geisser correction applied when necessary. In case of significant results of the ANOVA, exploratory post-hoc comparisons were performed using Student's $t$-tests (paired samples, two-tailed, $p<0.05$, not corrected for multiple comparisons) between the MEP amplitudes before and after PAS administration within one experimental condition and between the single time points within the same stimulation condition.

To exclude differences between baseline values of different conditions, also between first and second baseline values, we compared the respective values by Student's $t$-tests (paired samples, two-tailed, $p<0.05$, not corrected for multiple comparisons).

\section{RESULTS}

All subjects tolerated the procedure well. None of them reported any side effect of either citalopram or the stimulation.
The average baseline MEP values did not significantly differ between groups as revealed by Student's $t$-tests (paired samples, two-tailed, $p>0.05$ ). Citalopram alone did not have any impact on cortical excitability, as revealed by Student's $t$-tests between first and second baseline values (paired samples, two-tailed, $p>0.05$; Table 1).

The ANOVA revealed significant main effects of medication $(F(1)=5.345 ; p=0.039)$, stimulation $(F(1)=39.497$; $p<0.001)$, stimulation $\times$ time $(F(14)=15.593 ; p<0.001)$ and medication $\times$ time $(F(14)=2.456 ; p=0.004)$ interactions (for details, see Table 2). The main effect of medication is caused by similarly directed effects of citalopram on MEP amplitudes for PAS10, and PAS25. As compared with placebo medication, citalopram enhanced motor cortical excitability. The main effect of stimulation is due to relatively larger MEP amplitudes in the PAS25 condition, as compared with PAS10, irrespective of medication condition or time point. The interaction of stimulation $\mathrm{x}$ time refers to different time courses of MEP alterations generated by PAS10, and PAS25. MEP reductions induced by PAS10 lasted longer than those accomplished by PAS25, and were antagonistically directed for up to $90 \mathrm{~min}$ after stimulation, but not with regard to the later time points. Finally, the interaction of medication and time course is caused by the MEP-enhancing effect of citalopram on MEP amplitudes, as compared with placebo medication, during the first 30 (PAS25) or 90 (PAS10) min after PAS, but not for later time points.

Post-hoc Student's t-tests show that in the placebo medication conditions, MEPs were significantly enhanced for $30 \mathrm{~min}$ after PAS-25 stimulation and diminished for $90 \mathrm{~min}$ after PAS10 stimulation. Citalopram abolished PAS10-induced LTD-like plasticity and enhanced PAS25induced LTP-like plasticity, as compared with the respective placebo medication conditions. Student's $t$-tests show significant differences between drug and placebo conditions at all time points between 0 and $25 \mathrm{~min}$ after PAS10 administration and only at the single time point of $30 \mathrm{~min}$ after PAS25 (Figure 2).

For the effects of citalopram on PAS-induced plasticity with regard to the grand average calculated for the first 30 min after PAS, citalopram had a significant effect on focal

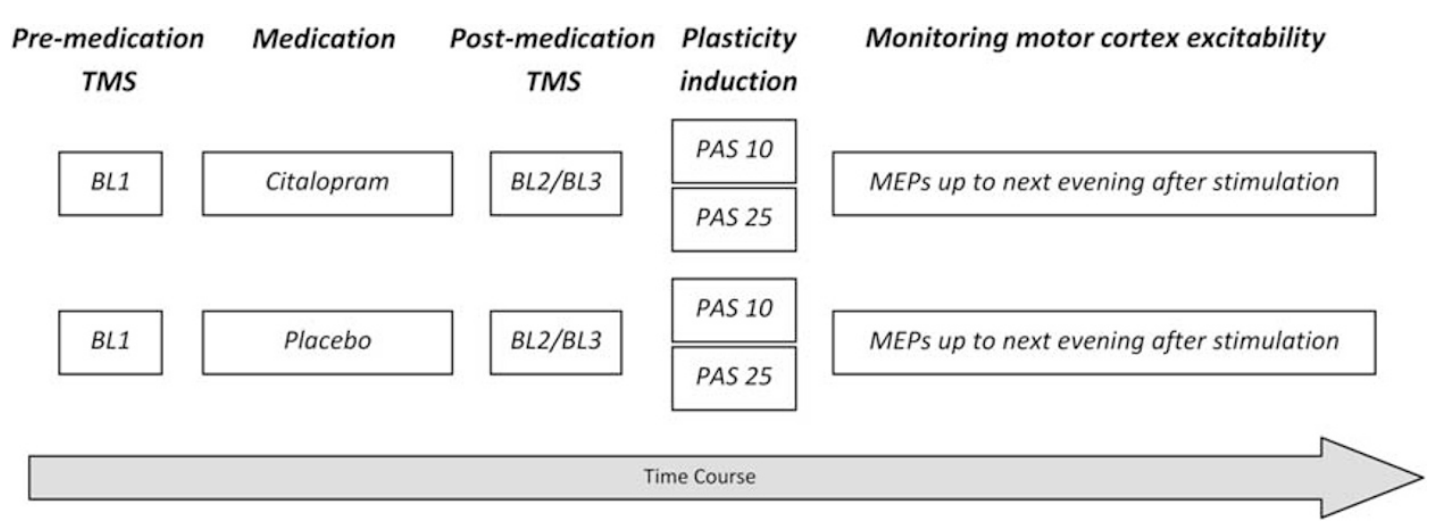

Figure I Course of the study. In the beginning of each session, before administration of citalopram or placebo medication, 25 baseline single-pulse MEPs were recorded at an intensity to elicit MEPs with peak-to-peak amplitudes of on average $1 \mathrm{mV}$. After $2 \mathrm{~h}$, the second baseline was recorded to explore the effect of medication on cortical plasticity, and adjusted, if necessary. After obtaining the second (or third) baseline, PAS was administered and 25 MEPs were recorded immediately after stimulation and at time points of 5, I0, 15, 20, 25, 30, 60, 90, and I 20 min after plasticity induction. Further transcranial magnetic stimulation (TMS) measurements were conducted in the evening of the same day (SE), next morning, at 0900 hours (NM), next noon, at I200 hours $(\mathrm{NN})$, and next evening, at $\sim 1800$ hours (NE). 
Table I MEP Amplitudes and Stimulation Intensity Before and After Citalopram Administration

\begin{tabular}{|c|c|c|c|c|c|}
\hline Stimulation & TMS parameter & Medication condition & Baseline I & Baseline 2 & Baseline 3 \\
\hline \multirow[t]{4}{*}{ PAS25 } & MEP & Citalopram & $1.04 \pm 0.07$ & $0.99 \pm 0.17$ & $0.99 \pm 0.14$ \\
\hline & & Placebo & $1.03 \pm 0.11$ & $0.93 \pm 0.23$ & $0.96 \pm 0.14$ \\
\hline & $\% \mathrm{MSO}$ & Citalopram & $49.3 \pm 9.81$ & $49.1 \pm 9.85$ & $49.3 \pm 9.98$ \\
\hline & & Placebo & $48.9 \pm 9.42$ & $48.9 \pm 9.42$ & $49.3 \pm 9.46$ \\
\hline \multirow[t]{2}{*}{ PASIO } & MEP & Citalopram & $1.04 \pm 0.12$ & $1.00 \pm 0.12$ & $1.00 \pm 0.10$ \\
\hline & & Placebo & $49.1 \pm 9.61$ & $49.1 \pm 9.61$ & $49.6 \pm 9.80$ \\
\hline
\end{tabular}

Shown are the mean MEP amplitudes \pm SD and stimulation intensity (percentage of maximum stimulator output, \%MSO) mean \pm SD of baselines I, 2 and 3. The intensity of TMS was adjusted to elicit MEPs with peak-to-peak amplitude of $\sim 1 \mathrm{mV}$ (baseline I). A second baseline (baseline 2) was recorded $2 \mathrm{~h}$ after citalopram or placebo intake to determine the impact of the drug on cortical excitability and adjusted if necessary (baseline 3). Student's t-tests revealed no significant differences between conditions ( $p>0.05)$.

Table 2 Results of the Repeated Measures ANOVA

\begin{tabular}{lccc}
\hline Factor & Df & $\boldsymbol{F}$ & $\boldsymbol{P}$ \\
\hline Medication & $\mid$ & 5.345 & $0.039^{*}$ \\
Stimulation & $\mid$ & 39.497 & $<0.00$ I* $^{*}$ \\
Time & $\mid 4$ & 0.723 & 0.749 \\
Medication $\times$ stimulation & $\mid$ & 0.543 & 0.476 \\
Medication $\times$ time & $\mid 4$ & 2.456 & $0.004^{*}$ \\
Stimulation $\times$ time & $\mid 4$ & 15.593 & $<0.00$ I* \\
Medication $\times$ stimulation $\times$ time & $\mid 4$ & 0.622 & 0.845 \\
\hline
\end{tabular}

*Significant results at $p<0.05$.

excitability-diminishing plasticity, as revealed by respective post-hoc Student's $t$-tests (Student's $t$-test, paired samples, two-tailed, $p=0.009$ ), whereas only a non-significant tendency towards excitability enhancement after PAS25 stimulation was detected (Student's $t$-test, paired samples, two-tailed, $p=0.126$ ) (Figure 3 ).

\section{DISCUSSION}

The results of this study show that serotonin has specific effects on PAS-induced motor cortex plasticity in healthy humans. It abolishes focal LTD-like and trendwise enhances focal LTP-like plasticity induced by PAS10 and PAS25, respectively.

These results go in line with previous studies (Nitsche et al, 2009; Normann et al, 2007). Chronic application of SSRI enhanced facilitatory plasticity and resulted in a shift of inhibitory plasticity of early visual-evoked potentials (VEPs) toward excitation (Normann et al, 2007) or restored LTP induction and suppressed LTD facilitation in distressed animals (Von Frijtag et al, 2001). For the human motor cortex, another study has demonstrated that a single dose of the SSRI citalopram results in enhancement and prolongation of anodal tDCS-induced LTP-like facilitation and conversion of cathodal tDCS-induced LTD-like plasticity into facilitation (Nitsche et al, 2009). In further accordance,
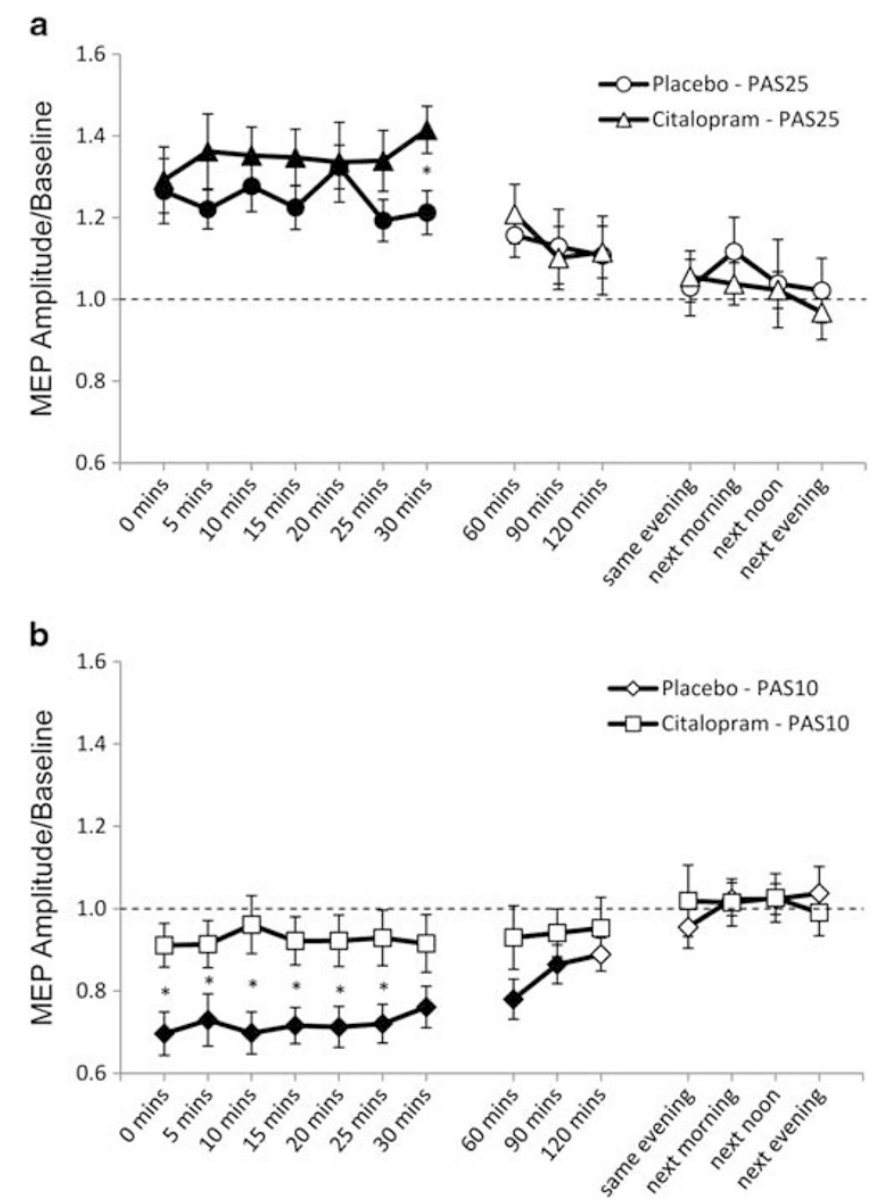

Figure 2 Impact of citalopram on paired associative stimulation (PAS)induced neuroplasticity. Shown are baseline-normalized MEP amplitudes after plasticity induction by PAS25 (a) and PASIO (b) under placebo or citalopram medication conditions up to the evening of the post-stimulation day. (a) In the placebo medication condition, PAS25 induced a significant excitability elevation up to $60 \mathrm{~min}$ after stimulation, which was enhanced, but not prolonged, by citalopram. (b). In the placebo medication condition, cortical excitability was significantly reduced after PASI0, this effect was abolished by citalopram. Error bars indicate SEM. Filled symbols indicate significant differences of post-stimulation MEP amplitudes from respective baseline values; asterisks indicate significant differences between the drug and placebo medication conditions at the same time points (Student's $t$-test, two-tailed, paired samples, $p<0.05$ ). 


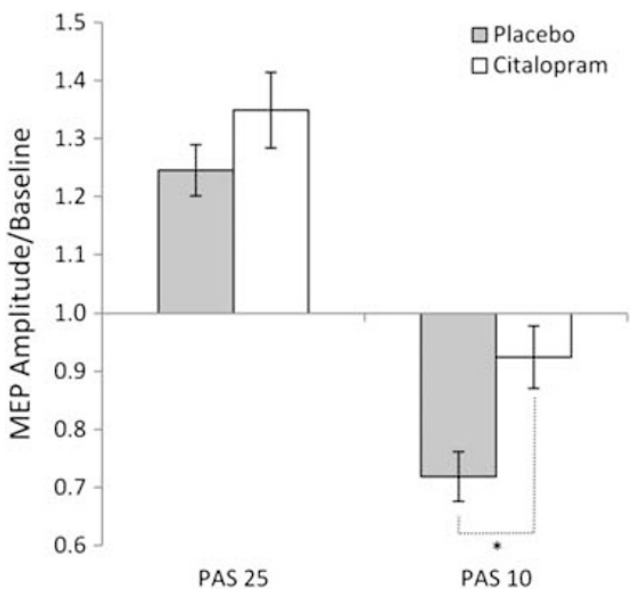

Figure 3 Citalopram enhances PAS25-induced excitatory plasticity and abolishes PASI0-induced inhibitory plasticity. Each column represents the mean of baseline-normalized MEP \pm SEM amplitudes until 30 min after stimulation. Asterisks indicate significant differences between drug and placebo conditions (Student's t-test, two-tailed, paired samples, $p<0.05$ ).

animal studies have shown that serotonin can enhance LTP (Huang and Kandel, 2007; Kojic et al, 1997; Machacek et al, 2001; Mori et al, 2001; Ohashi et al, 2002; Park et al, 2012), block the stress-caused inhibition of LTP (Ryan et al, 2008) or block LTD (Normann et al, 2007). Activation of 5-HT receptors was furthermore shown to reverse LTD induction or convert it into LTP (Costa et al, 2012; Kemp and Manahan-Vaughan, 2005).

However, activation of serotoninergic receptors also had opposing results on plasticity in other studies. Some studies have shown negative or no effect of serotonin on LTP induction (Edagawa et al, 1998; Huang and Kandel, 2007; Kojima et al, 2003; Normann et al, 2007; Sanberg et al, 2006), which can be explained by activation of different serotoninergic receptor subtypes, stage of brain development or dosage and frequency of application of 5-HT agonists or antagonists (Mori et al, 2001; Park et al, 2012; Staubli and Otaky, 1994). To explore the reasons of such opposing results, future studies should address specific serotoninergic receptor subtypes, using different 5-HTreceptor agonist or antagonist drugs. It might also make sense to explore different dosages of serotoninergic receptor agonists, as it has been demonstrated that other neuromodulators, such as dopamine, have dose-dependent effects on focal and non-focal plasticity in humans (Monte-Silva et al, 2009; Monte-Silva et al, 2010).

\section{Proposed Mechanisms of Action}

After-effects of tDCS and PAS are NMDA- and $\mathrm{Ca}^{2+}$ dependent (Nitsche et al, 2003a; Stefan et al, 2002; Wolters et al, 2003). It has been shown that serotonin facilitates NMDA receptor-dependent LTP (Park et al, 2012). Furthermore, serotonin affects $\mathrm{K}^{+}$-channels and reduces membrane potassium conductance (Andrade and Chaput, 1991; Bockaert et al, 1992; Choi and Hahn, 2012; Jeong et al, 2012; Panicker et al, 1991). In case of enhanced serotonin level, these factors could result in membrane depolarization and enhanced $\mathrm{Ca}^{2+}$ influx into the postsynaptic neurons through calcium channels and NMDA receptors (Gu, 2002).
The direction of induced plasticity depends on the amount of intracellular calcium, with low concentration inducing LTD, high concentration inducing LTP and medium concentration resulting in no plasticity (Cho et al, 2001; Lisman, 2001). Therefore, the above-mentioned serotonintriggered enhancement of calcium influx could have resulted in a tendency towards facilitation of PAS25induced LTP-like plasticity, similar to that accomplished by anodal tDCS in a previous study (Nitsche et al, 2009). Unlike for cathodal tDCS, where neuroplastic excitability diminutions were converted to facilitation by citalopram (Nitsche et al, 2009), the drug abolished PAS10-induced LTD-like plasticity in the present study. This can be explained by differences of the respective plasticity induction protocols. Plasticity induced by tDCS is accomplished by long, tonic depolarization of large neuronal populations and activation of voltage-dependent calcium channels, whereas depolarization caused by PAS is short-lasting and affects only small groups of neurons. Therefore the increase of intracellular calcium might be smaller after PAS administration, as compared with tDCS. Given the dependency of plasticity induction from intracellular calcium level, thus the calcium increase accomplished by citalopram might have been sufficient to induce LTP-like plasticity in case of cathodal tDCS, but not for PAS10. This also explains why the shift in excitability toward PAS25-induced excitatory plasticity enhancement is not as clear as in case of anodal tDCS. This hypothesis should however be tested more directly in future experiments.

The role of specific 5-HT receptors in the impact of citalopram on PAS-generated plasticity is not clear. 5-HT2 and 5-HT3 are candidate receptors. The 5-HT3 receptor enhances $\mathrm{Ca}^{2+}$ conductance, leading to neuronal depolarization, while the 5-HT2 receptor induces $\mathrm{Ca}^{2+}$ release from intracellular stores (Reiser et al, 1989). Accordingly, activation of 5-HT2 receptors has a facilitatory effect on NMDA receptor-dependent LTP induction in the visual cortex of adult rats (Park et al, 2012). Finally, serotonin affects cholinergic (Consolo et al, 1994; Matsumoto et al, 2001; Yamaguchi et al, 1997), GABAergic (Roerig and Katz, 1997; Waider et al, 2012), nicotinergic (Zaniewska et al, 2009), and dopaminergic (Gobert and Millan, 1999; Wood and Wren, 2008) systems, which have a major impact on stimulation-induced plasticity in humans (Kuo et al, 2007; Kuo et al, 2008; Monte-Silva et al, 2009; Monte-Silva et al, 2010; Nitsche et al, 2004; Thirugnanasambandam et al, 2012). While it cannot be ruled out completely that serotonin enhancement affected plasticity partially by its impact on one of these neuromodulatory systems, a profound contribution seems unlikely, because the impact of citalopram on tDCS-, and PAS-induced plasticity differs relevantly from those of other neuromodulators. Specifically the above-mentioned studies show that dopamine, acetylcholine, and nicotine have a focusing effect on LTP-like motor cortex plasticity, which is hypothesized to be advantageous for task performance if stable information processing is needed (eg, a simple task which requires uniform action). In contrast, de-focusing-as obtained by citalopram, which enhances focal and non-focal LTP-like plasticity, as shown in the present study, and in a previous study of our group (Nitsche et al, 2009) might be advantageous when a task requires flexible information 
processing (eg, complex problem solving) (Seamans and Yang, 2004). This hypothetical specific impact of serotonin on ask performance should be explored in future experiments.

\section{General Remarks}

PAS is assumed to be related to learning processes as it shares some characteristics with STDP, such as timing and synchronization of two pulses as a requirement to induce plasticity. Therefore, the results of the present and other studies, which show an enhancement of LTP-like PASinduced plasticity, and a reduction of LTD-like plasticity by SSRIs (Nitsche et al, 2009; Normann et al, 2007), make these drugs interesting substances for improving learning and motor performance in several clinical conditions (eg, in motor or speech rehabilitation after stroke). Especially with regard to stroke and depression, where LTP-like plasticity seems to be reduced, and/or LTD-like plasticity enhanced by disease-related processes (Foy et al, 1987; Schaechter, 2004; Traversa et al, 1997; Traversa et al, 1998; Turton et al, 1996; Xu et al, 1997), the results of the present study can at least partially explain why SSRIs can reduce symptoms. In accordance with the LTP-enhancing effect of SSRI with regard to stimulation-induced plasticity (Nitsche et al, 2009), a synergistic effect of tDCS and SSRI medication on major depression has been described recently, most probably related to the increased efficacy of anodal tDCSinduced LTP-like plasticity under SSRI (Brunoni et al, 2013).

One possible limitation to our study could be that 1-week intersession interval might not be sufficient to rule out any interference effects definitely, as suggested by the results of a recent study (Rajji et al, 2011), where PAS25 and PAS10 had a significant impact on motor task performance 1 week after PAS administration. In our study, MEP amplitudes recorded the day after plasticity induction however show no effect of PAS with or without citalopram on motor cortex excitability. Moreover, because of the randomized order of conditions, we would not expect a systematic impact of any minor carryover effect on the results. Finally, previous studies of our group in which a similar procedure was performed showed PAS plasticity effects in the placebo medication conditions, which are comparable to the experiments of other groups, in which not such a frequent repetition of sessions was performed (Kuo et al, 2008; Monte-Silva et al, 2009; Monte-Silva et al, 2010; Stefan et al, 2000; Stefan et al, 2004; Thirugnanasambandam et al, 2012). Therefore, late-phase plasticity is unlikely to have compromised the results of the present experiments.

Interestingly, chronic application of SSRI has different effects on cortical excitability as compared wth single-dose application, although both conditions resulted in functional improvement of motor performance (Gerdelat-Mas et al, 2005; Loubinoux et al, 2002a; Loubinoux et al, 2002b). Clinical studies show that it takes several weeks to obtain therapeutic effects of SSRIs. This suggests an involvement of different mechanisms, such as desensitization and downregulation of receptors, or reduction of serotonin synthesis in the effects of chronic administration of SSRIs (Blier and Bouchard, 1994; Pineyro et al, 1994; Yamane et al, 2001), which should be explored in larger detail in future studies.

\section{FUNDING AND DISCLOSURE}

M-FK, and GB received no financial support or compensation from any individual or corporate entity over the past 3 years for research or professional service and there are no personal financial holdings that could be perceived as constituting a potential conflict of interest. WP is member of Advisory Boards of GSK, UCB, Desitin. MAN is member of Advisory Boards of UCB, Eisai, GSK, and Neuroelectronics.

\section{ACKNOWLEDGEMENTS}

This work was partially supported by the TechnionNiedersachsen Fund.

\section{REFERENCES}

Andrade R, Chaput Y (1991). 5-Hydroxytryptamine4-like receptors mediate the slow excitatory response to serotonin in the rat hippocampus. J Pharmacol Exp Ther 257: 930-937.

Bert B, Fink H, Rothe J, Walstab J, Bonisch H (2008). Learning and memory in 5-HT(1A)-receptor mutant mice. Behav Brain Res 195: 78-85.

Bezchlibnyk-Butler K, Aleksic I, Kennedy SH (2000). Citaloprama review of pharmacological and clinical effects. J Psychiatry Neurosci 25: 241-254.

Blier P, Bouchard C (1994). Modulation of 5-HT release in the guinea-pig brain following long-term administration of antidepressant drugs. Br J Pharmacol 113: 485-495.

Bockaert J, Fozard JR, Dumuis A, Clarke DE (1992). The 5-HT4 receptor: a place in the sun. Trends Pharmacol Sci 13: 141-145.

Brunoni AR, Valiengo L, Baccaro A, Zanao TA, de Oliveira JF, Goulart A et al (2013). The sertraline vs electrical current therapy for treating depression clinical study: results from a factorial, randomized, controlled trial. JAMA Psychiatry 70: 1-9.

Caspi A, Sugden K, Moffitt TE, Taylor A, Craig IW, Harrington H et al (2003). Influence of life stress on depression: moderation by a polymorphism in the 5-HTT gene. Science 301: 386-389.

Cho K, Aggleton JP, Brown MW, Bashir ZI (2001). An experimental test of the role of postsynaptic calcium levels in determining synaptic strength using perirhinal cortex of rat. J Physiol 532(Pt 2): 459-466.

Choi JS, Hahn SJ (2012). Duloxetine blocks cloned Kv4.3 potassium channels. Brain Res 1466: 15-23.

Chollet F, Tardy J, Albucher JF, Thalamas C, Berard E, Lamy C et al (2011). Fluoxetine for motor recovery after acute ischaemic stroke (FLAME): a randomised placebo-controlled trial. Lancet Neurol 10: 123-130.

Christoffel DJ, Golden SA, Russo SJ (2011). Structural and synaptic plasticity in stress-related disorders. Rev Neurosci 22: 535-549.

Consolo S, Arnaboldi S, Giorgi S, Russi G, Ladinsky H (1994). 5 -HT4 receptor stimulation facilitates acetylcholine release in rat frontal cortex. Neuroreport 5: 1230-1232.

Costa L, Spatuzza M, D'Antoni S, Bonaccorso CM, Trovato C, Musumeci SA et al (2012). Activation of 5-HT7 serotonin receptors reverses metabotropic glutamate receptor-mediated synaptic plasticity in wild-type and Fmr1 knockout mice, a model of Fragile X syndrome. Biol Psychiatry 72: 924-933.

Dam M, Tonin P, De Boni A, Pizzolato G, Casson S, Ermani M et al (1996). Effects of fluoxetine and maprotiline on functional recovery in poststroke hemiplegic patients undergoing rehabilitation therapy. Stroke 27: 1211-1214.

Edagawa Y, Saito H, Abe K (1998). 5-HT1A receptor-mediated inhibition of long-term potentiation in rat visual cortex. Eur J Pharmacol 349: 221-224. 
Foy MR, Stanton ME, Levine S, Thompson RF (1987). Behavioral stress impairs long-term potentiation in rodent hippocampus. Behav Neural Biol 48: 138-149.

Garcia R (2002). Stress, synaptic plasticity, and psychopathology. Rev Neurosci 13: 195-208.

Gerdelat-Mas A, Loubinoux I, Tombari D, Rascol O, Chollet F, Simonetta-Moreau M (2005). Chronic administration of selective serotonin reuptake inhibitor (SSRI) paroxetine modulates human motor cortex excitability in healthy subjects. Neuroimage 27: 314-322.

Geyer MA (1996). Serotonergic functions in arousal and motor activity. Behav Brain Res 73: 31-35.

Gobert A, Millan MJ (1999). Serotonin (5-HT)2A receptor activation enhances dialysate levels of dopamine and noradrenaline, but not 5-HT, in the frontal cortex of freely-moving rats. Neuropharmacology 38: 315-317.

$\mathrm{Gu} \mathrm{Q}$ (2002). Neuromodulatory transmitter systems in the cortex and their role in cortical plasticity. Neuroscience 111: 815-835.

Hasbroucq T, Rihet P, Blin O, Possamai CA (1997). Serotonin and human information processing: fluvoxamine can improve reaction time performance. Neurosci Lett 229: 204-208.

Henn FA, Vollmayr B (2004). Basic pathophysiological mechanisms in depression: what are they and how might they affect the course of the illness? Pharmacopsychiatry 37(Suppl 2): S152-S156.

Holderbach R, Clark K, Moreau JL, Bischofberger J, Normann C (2007). Enhanced long-term synaptic depression in an animal model of depression. Biol Psychiatry 62: 92-100.

Huang YY, Kandel ER (2007). 5-Hydroxytryptamine induces a protein kinase $\mathrm{A} /$ mitogen-activated protein kinase-mediated and macromolecular synthesis-dependent late phase of long-term potentiation in the amygdala. J Neurosci 27: 3111-3119.

Jacobs BL, Fornal CA (1997). Serotonin and motor activity. Curr Opin Neurobiol 7: 820-825.

Jeong I, Yoon SH, Hahn SJ (2012). Effects of dapoxetine on cloned Kv1.5 channels expressed in CHO cells. Naunyn Schmiedebergs Arch Pharmacol 385: 707-716.

Kemp A, Manahan-Vaughan D (2005). The 5-hydroxytryptamine4 receptor exhibits frequency-dependent properties in synaptic plasticity and behavioural metaplasticity in the hippocampal CA1 region in vivo. Cereb Cortex 15: 1037-1043.

Kojic L, Gu Q, Douglas RM, Cynader MS (1997). Serotonin facilitates synaptic plasticity in kitten visual cortex: an in vitro study. Brain Res Dev Brain Res 101: 299-304.

Kojima T, Matsumoto M, Togashi H, Tachibana K, Kemmotsu O, Yoshioka M (2003). Fluvoxamine suppresses the long-term potentiation in the hippocampal CA1 field of anesthetized rats: an effect mediated via 5-HT1A receptors. Brain Res 959: $165-168$.

Kragh-Sorensen P, Overo KF, Petersen OL, Jensen K, Parnas W (1981). The kinetics of citalopram: single and multiple dose studies in man. Acta Pharmacol Toxicol (Copenh) 48: 53-60.

Kuo MF, Grosch J, Fregni F, Paulus W, Nitsche MA (2007). Focusing effect of acetylcholine on neuroplasticity in the human motor cortex. J Neurosci 27: 14442-14447.

Kuo MF, Paulus W, Nitsche MA (2008). Boosting focally-induced brain plasticity by dopamine. Cereb Cortex 18: 648-651.

Lisman JE (2001). Three Ca2 + levels affect plasticity differently: the LTP zone, the LTD zone and no man's land. J Physiol 532(Pt 2): 285.

Loubinoux I, Boulanouar K, Ranjeva JP, Carel C, Berry I, Rascol O et al (1999). Cerebral functional magnetic resonance imaging activation modulated by a single dose of the monoamine neurotransmission enhancers fluoxetine and fenozolone during hand sensorimotor tasks. J Cereb Blood Flow Metab 19: 1365-1375.

Loubinoux I, Pariente J, Boulanouar K, Carel C, Manelfe C, Rascol $\mathrm{O}$ et al (2002a). A single dose of the serotonin neurotransmission agonist paroxetine enhances motor output: double-blind, placebo-controlled, fMRI study in healthy subjects. Neuroimage 15: $26-36$.
Loubinoux I, Pariente J, Rascol O, Celsis P, Chollet F (2002b). Selective serotonin reuptake inhibitor paroxetine modulates motor behavior through practice. A double-blind, placebocontrolled, multi-dose study in healthy subjects. Neuropsychologia 40: 1815-1821.

Loubinoux I, Tombari D, Pariente J, Gerdelat-Mas A, Franceries X, Cassol E et al (2005). Modulation of behavior and cortical motor activity in healthy subjects by a chronic administration of a serotonin enhancer. Neuroimage 27: 299-313.

Machacek DW, Garraway SM, Shay BL, Hochman S (2001). Serotonin 5-HT(2) receptor activation induces a long-lasting amplification of spinal reflex actions in the rat. J Physiol 537(Pt 1): 201-207.

Matsumoto M, Togashi H, Mori K, Ueno K, Ohashi S, Kojima T et al (2001). Evidence for involvement of central 5-HT(4) receptors in cholinergic function associated with cognitive processes: behavioral, electrophysiological, and neurochemical studies. J Pharmacol Exp Ther 296: 676-682.

Meneses A (1999). 5-HT system and cognition. Neurosci Biobehav Rev 23: 1111-1125.

Monte-Silva K, Kuo MF, Thirugnanasambandam N, Liebetanz D, Paulus W, Nitsche MA (2009). Dose-dependent inverted U-shaped effect of dopamine (D2-like) receptor activation on focal and nonfocal plasticity in humans. J Neurosci 29: 6124-6131.

Monte-Silva K, Liebetanz D, Grundey J, Paulus W, Nitsche MA (2010). Dosage-dependent non-linear effect of L-dopa on human motor cortex plasticity. J Physiol 588(Pt 18): 3415-3424.

Mori K, Togashi H, Kojima T, Matsumoto M, Ohashi S, Ueno K et al (2001). Different effects of anxiolytic agents, diazepam and 5-HT(1A) agonist tandospirone, on hippocampal long-term potentiation in vivo. Pharmacol Biochem Behav 69: 367-372.

Nitsche MA, Cohen LG, Wassermann EM, Priori A, Lang N, Antal A et al (2008). Transcranial direct current stimulation: state of the art 2008. Brain Stimul 1: 206-223.

Nitsche MA, Fricke K, Henschke U, Schlitterlau A, Liebetanz D, Lang $\mathrm{N}$ et al (2003a). Pharmacological modulation of cortical excitability shifts induced by transcranial direct current stimulation in humans. J Physiol 553(Pt 1): 293-301.

Nitsche MA, Kuo MF, Karrasch R, Wachter B, Liebetanz D, Paulus W (2009). Serotonin affects transcranial direct current-induced neuroplasticity in humans. Biol Psychiatry 66: 503-508.

Nitsche MA, Liebetanz D, Schlitterlau A, Henschke U, Fricke K, Frommann $\mathrm{K}$ et al (2004). GABAergic modulation of DC stimulation-induced motor cortex excitability shifts in humans. Eur J Neurosci 19: 2720-2726.

Nitsche MA, Nitsche MS, Klein CC, Tergau F, Rothwell JC, Paulus W (2003b). Level of action of cathodal DC polarisation induced inhibition of the human motor cortex. Clin Neurophysiol 114: 600-604.

Nitsche MA, Paulus W (2000). Excitability changes induced in the human motor cortex by weak transcranial direct current stimulation. J Physiol 527(Pt 3): 633-639.

Nitsche MA, Paulus W (2001). Sustained excitability elevations induced by transcranial DC motor cortex stimulation in humans. Neurology 57: 1899-1901.

Nitsche MA, Roth A, Kuo MF, Fischer AK, Liebetanz D, Lang N et al (2007). Timing-dependent modulation of associative plasticity by general network excitability in the human motor cortex. J Neurosci 27: 3807-3812.

Normann C, Schmitz D, Furmaier A, Doing C, Bach M (2007). Long-term plasticity of visually evoked potentials in humans is altered in major depression. Biol Psychiatry 62: 373-380.

Ohashi S, Matsumoto M, Otani H, Mori K, Togashi H, Ueno K et al (2002). Changes in synaptic plasticity in the rat hippocampomedial prefrontal cortex pathway induced by repeated treatments with fluvoxamine. Brain Res 949: 131-138.

Oldfield RC (1971). The assessment and analysis of handedness: the Edinburgh inventory. Neuropsychologia 9: 97-113. 
Panicker MM, Parker I, Miledi R (1991). Receptors of the serotonin 1C subtype expressed from cloned DNA mediate the closing of $\mathrm{K}+$ membrane channels encoded by brain mRNA. Proc Natl Acad Sci USA 88: 2560-2562.

Pariente J, Loubinoux I, Carel C, Albucher JF, Leger A, Manelfe C et al (2001). Fluoxetine modulates motor performance and cerebral activation of patients recovering from stroke. Ann Neurol 50: 718-729.

Park SW, Jang HJ, Cho KH, Kim MJ, Yoon SH, Rhie DJ (2012). Developmental switch of the serotonergic role in the induction of synaptic long-term potentiation in the rat visual cortex. Korean J Physiol Pharmacol 16: 65-70.

Pineyro G, Blier P, Dennis T, de Montigny C (1994). Desensitization of the neuronal 5-HT carrier following its long-term blockade. J Neurosci 14(5 Pt 2): 3036-3047.

Popoli M, Gennarelli M, Racagni G (2002). Modulation of synaptic plasticity by stress and antidepressants. Bipolar Disord 4: 166-182.

Purpura DP, McMurtry JG (1965). Intracellular activities and evoked potential changes during polarization of motor cortex. J Neurophysiol 28: 166-185.

Rajji TK, Liu SK, Frantseva MV, Mulsant BH, Thoma J, Chen R et al (2011). Exploring the effect of inducing long-term potentiation in the human motor cortex on motor learning. Brain Stimul 4: 137-144.

Reiser G, Donie F, Binmoller FJ (1989). Serotonin regulates cytosolic $\mathrm{Ca} 2+$ activity and membrane potential in a neuronal and in a glial cell line via 5-HT3 and 5-HT2 receptors by different mechanisms. J Cell Sci 93(Pt 3): 545-555.

Robol E, Fiaschi A, Manganotti P (2004). Effects of citalopram on the excitability of the human motor cortex: a paired magnetic stimulation study. J Neurol Sci 221: 41-46.

Rocher C, Spedding M, Munoz C, Jay TM (2004). Acute stressinduced changes in hippocampal/prefrontal circuits in rats: effects of antidepressants. Cereb Cortex 14: 224-229.

Roerig B, Katz LC (1997). Modulation of intrinsic circuits by serotonin 5-HT3 receptors in developing ferret visual cortex. J Neurosci 17: 8324-8338.

Ryan BK, Anwyl R, Rowan MJ (2008). 5-HT2 receptor-mediated reversal of the inhibition of hippocampal long-term potentiation by acute inescapable stress. Neuropharmacology 55: 175-182.

Sanberg CD, Jones FL, Do VH, Dieguez D, Derrick BE Jr. (2006). 5-HT1a receptor antagonists block perforant path-dentate LTP induced in novel, but not familiar, environments. Learn Mem 13: $52-62$.

Schaechter JD (2004). Motor rehabilitation and brain plasticity after hemiparetic stroke. Prog Neurobiol 73: 61-72.

Seamans JK, Yang CR (2004). The principal features and mechanisms of dopamine modulation in the prefrontal cortex. Prog Neurobiol 74: 1-58.

Shors TJ, Seib TB, Levine S, Thompson RF (1989). Inescapable versus escapable shock modulates long-term potentiation in the rat hippocampus. Science 244: 224-226.

Staubli U, Otaky N (1994). Serotonin controls the magnitude of LTP induced by theta bursts via an action on NMDA-receptormediated responses. Brain Res 643: 10-16.

Stefan K, Kunesch E, Benecke R, Cohen LG, Classen J (2002). Mechanisms of enhancement of human motor cortex excitability induced by interventional paired associative stimulation. J Physiol 543(Pt 2): 699-708.

Stefan K, Kunesch E, Cohen LG, Benecke R, Classen J (2000). Induction of plasticity in the human motor cortex by paired associative stimulation. Brain 123(Pt 3): 572-584.

Stefan K, Wycislo M, Classen J (2004). Modulation of associative human motor cortical plasticity by attention. J Neurophysiol 92: 66-72.

Thirugnanasambandam N, Grundey J, Adam K, Drees A, Skwirba AC, Lang $\mathrm{N}$ et al (2012). Nicotinergic impact on focal and nonfocal neuroplasticity induced by non-invasive brain stimulation in non-smoking humans. Neuropsychopharmacology 36: 879-886.

Traversa R, Cicinelli P, Bassi A, Rossini PM, Bernardi G (1997). Mapping of motor cortical reorganization after stroke. A brain stimulation study with focal magnetic pulses. Stroke 28: 110-117.

Traversa R, Cicinelli P, Pasqualetti P, Filippi M, Rossini PM (1998). Follow-up of interhemispheric differences of motor evoked potentials from the 'affected' and 'unaffected' hemispheres in human stroke. Brain Res 803: 1-8.

Turton A, Wroe S, Trepte N, Fraser C, Lemon RN (1996). Contralateral and ipsilateral EMG responses to transcranial magnetic stimulation during recovery of arm and hand function after stroke. Electroencephalogr Clin Neurophysiol 101: 316-328

Von Frijtag JC, Kamal A, Reijmers LG, Schrama LH, van den Bos R, Spruijt BM (2001). Chronic imipramine treatment partially reverses the long-term changes of hippocampal synaptic plasticity in socially stressed rats. Neurosci Lett 309: 153-156.

Waider J, Proft F, Langlhofer G, Asan E, Lesch KP, Gutknecht L (2012). GABA concentration and GABAergic neuron populations in limbic areas are differentially altered by brain serotonin deficiency in Tph2 knockout mice. Histochem Cell Biol 139: 267-281.

Wolters A, Sandbrink F, Schlottmann A, Kunesch E, Stefan K, Cohen LG et al (2003). A temporally asymmetric Hebbian rule governing plasticity in the human motor cortex. $J$ Neurophysiol 89: 2339-2345.

Wood MD, Wren PB (2008). Serotonin-dopamine interactions: implications for the design of novel therapeutic agents for psychiatric disorders. Prog Brain Res 172: 213-230.

Xu L, Anwyl R, Rowan MJ (1997). Behavioural stress facilitates the induction of long-term depression in the hippocampus. Nature 387: 497-500.

Yamaguchi T, Suzuki M, Yamamoto M (1997). Facilitation of acetylcholine release in rat frontal cortex by indeloxazine hydrochloride: involvement of endogenous serotonin and 5HT4 receptors. Naunyn Schmiedebergs Arch Pharmacol 356: $712-720$

Yamane F, Okazawa H, Blier P, Diksic M (2001). Reduction in serotonin synthesis following acute and chronic treatments with paroxetine, a selective serotonin reuptake inhibitor, in rat brain: an autoradiographic study with alpha-[14C]methyl-L-tryptophan(2). Biochem Pharmacol 62: 1481-1489.

Zaniewska M, McCreary AC, Filip M (2009). Interactions of serotonin (5-HT)2 receptor-targeting ligands and nicotine: locomotor activity studies in rats. Synapse 63: 653-661. 